\title{
Community mental health care
}

Ghana Med J 2019; 53(2): 88-89 doi: http://dx.doi.org/10.4314/gmj.v53i2.1

Worldwide, mental health care has gone through four eras and four revolutions: The era of the Dark Ages of superstition when mental illnesses were thought to be an affliction of the spiritual world. This was the era of the papal-sponsored 1487 publication 'Malleus Maleficarum' ('Hammer of Witches') during the period of the Inquisition, which allowed the burning of suspected witches among whom were persons with mental illness. This era ended with the revolution that led to the unchaining and moral treatment offered by Pinel in 1793. The second revolution was the era of scientific understanding of the mind, demonstrated by the studies and theories of Sigmund Freud (1856 to 1939) and other collaborators, through to the invention of electroconvulsive therapy (ECT) in the year 1938, by Cerletti and Bini.

The third revolution for mental health care was the introduction of chlorpromazine in 1952 and the subsequent discovery of other psychotropic substances for psychosis, depression, anxiety, and other conditions. The efficacy and the near miracle of these chemicals in giving back to patients their life, coupled with the challenges of institutional care which included poor hygiene and quality of care, led to socio-political movements to close down many Victorian Asylums. ${ }^{1}$ This introduced the fourth major revolution in the 1960s being the role of the community in mental health care.

Granted, some would consider the fact of treating comorbid physical illnesses alongside mental conditions as rather the fourth major revolution in psychiatry. ${ }^{2} \mathrm{We}$ are, however, looking at the community component of mental health care as a major revolution. This era had a major boost by the Alma Ata Declaration of Primary Health Care in $1978^{3}$ which has been restated as the Astana Declaration of $2018^{4}$, reaffirming primary health care and the role of the community.

In Ghana, even before the Alma Ata Declaration, a series of measures were put in place to extend mental health care to the community. Between 1972 and 1973 mental health care spread in the Greater Accra Region to outside the Accra Psychiatric Hospital and eventually to all the ten regions of Ghana. In 1997 there was another boost for community care with the introduction of the WHO programme, 'Nations for Mental Health' by which general practitioners were given some training in mental health care in a bid to integrate mental health into general health care. In spite of these efforts, mental health care largely remained institutional care in Ghana.
The major boost to community care in Ghana, however, was the enactment of the Mental Health Act, 2012 (Act 846) of the Republic of Ghana, which authoritatively changed the paradigm of mental health care from institutional care to community care, with the establishment of regional mental health subcommittees and coordinators, with their district equivalents soon to be established. Since then, community mental health care is the order in Ghana, and more patients are seen outside the psychiatric hospitals than within psychiatric hospitals.

The advantages of community mental health care cannot be overemphasized. Institutional care worsens stigmatization of patients as it leads to labelling of patients, while community care reduces this stigma. Institutional care leads to 'institutional neurosis' where patients feel happy at the institutions and do not want to go home; they do not feel they belong to the outside world and always find a reason to return to the institutions. Institutions are more expensive to run and maintain and often there are unsanitary conditions to reckon with. Institutions keep patients for too long to recover leading to loss of productivity and adversely affecting the national economy.

These are obvious ills of institutional care for mental health for which the drive towards community care is appropriate. Part of community care is the integration of mental health into general health care where every health facility should be able to see patients with mental health conditions just as they see general health or physical health conditions. This is more convenient for patients and their caregivers as they can get the same attention for their physical health needs at the same premises.

In this issue of the journal is an article comparing the quality of life of patients treated in an institution to that of patients treated in the community. The study found no difference. This is good news for it supports the concept of community-oriented care as equally effective in improving the quality of life of recovered patients. Indeed Thornicroft and Tansella, while arguing that we need to seek a balance between hospital and community care, nevertheless admit that low-resource countries, such as ours in Ghana and West Africa, should focus on establishing and improving mental health services within primary care settings and use specialist services as a backup. ${ }^{5}$ Community mental health care is the way forward for effective mental health care.

\section{Dr Akwasi O. Osei FGCP, Chief Executive Mental Health Authority, Accra.}


E-mail: akwasiosei2014@gmail.com

Conflict of interest: None declared

\section{REFERENCES}

1. Hellen Killaspy. From the asylum to community care: learning from experience. British Medical Bulletin 2006; 79-80 (1): 245-258

2. Shiv Gautam Fourth revolution in psychiatry - addressing comorbidity with chronic physical disorders. Indian J Psychiatry 2010 Jul-Sep: 52(3): 213219. doi: 10.4103/0019-5545.70973
3. https://www.who.int/publications/almaata_declaration_en.pdf

4. https://www.who.int/primary-health/conferencephe/declaration

5. Thornicroft G, Tansella M (2003). What are the arguments for community-based mental health care? Copenhagen, WHO Regional Office for Europe (Health Evidence Network report:

http://www.euro.who.int/document/E82976.pdf

Copyright (C) The Author(s). This is an Open Access article under the CC BY license. 